\title{
Premarital and prenatal screening for cystic fibrosis: Experience in the Ashkenazi Jewish population
}

\author{
Ruth Kornreich, $P h D^{1}$, Josef Ekstein ${ }^{2}$, Lisa Edelmann, $P h D^{1}$ and Robert J. Desnick, PhD, $M D^{1}$
}

\begin{abstract}
Purpose: Since the early 1990s, Dor Yeshorim (DY) and the Mount Sinai School of Medicine (MSSM) have conducted premarital and prenatal carrier screening for cystic fibrosis (CF) in the Ashkenazi Jewish (AJ) population as part of their genetic testing programs, respectively. Together, over 170,000 screenees have been tested. In this study, we report the CF mutation frequencies in over 110,000 screenees who reportedly were of $100 \% \mathrm{AJ}$ descent from the DY program and MSSM. In addition, the CF mutation frequencies in a group of $>7,000$ screenees for AJ diseases who were of $<100 \%$ AJ descent are reported. Methods: Testing for CF mutations was performed by either PCR and restriction digestion or ASO hybridization analyses at MSSM or sent to various academic and commercial laboratories by DY. Results: The overall (and individual) carrier frequency for the five common AJ mutations, W1282X (0.020), $\Delta \mathrm{F} 508$ (0.012), G542X (0.0024), 3849+10kb C > T (0.0020), and N1303K (0.0016), among screenees who were $100 \% \mathrm{AJ}$ was 1 in 26 ; when $\mathrm{D} 1152 \mathrm{H}$ and the rare $1717-1 \mathrm{G}>\mathrm{A}$ were included, the overall carrier frequency increased to $\approx 1$ in 23 . In four families with $\mathrm{D} 1152 \mathrm{H}$, five compound heterozygotes for $\mathrm{D} 1152 \mathrm{H}$ and W1282X ( $n=2), \Delta F 508$ (1) or 3849+10kb C >T (1) were identified. In contrast, the carrier frequency for screenees reporting $<100 \%$ AJ descent was $\approx 1$ in 30 for the seven mutations. Conclusions: The carrier frequency for five common CF mutations in a large 100\% AJ sample increased from 1 in 26 to 1 in 23 when D1152H was included in the panel. Addition of $\mathrm{D} 1152 \mathrm{H}$ to mutation panels when screening the AJ population should be considered because compound heterozygosity is associated with a variable disease phenotype. Further studies to delineate the phenotype of CF patients with this mutation are needed. Genet Med 2004:6(5):415-420.
\end{abstract}

Key Words: cystic fibrosis, Ashkenazi Jews, D1152H, carrier screening

Cystic fibrosis (CF) is one of the most common recessively inherited severe disorders among Caucasians. The disease results from mutations in the CF transmembrane conductance regulator (CFTR) gene and over 1000 different mutations have been identified. ${ }^{1}$ Among these, the $\Delta$ F508 mutation is the most common with frequencies ranging from $18 \%$ to $88 \%$ in different ethnic, demographic, and racial groups. ${ }^{2}$ Carrier screening for common CFTR mutations in Caucasians have revealed frequencies from $\approx 1$ in 20 to 1 in 40 , depending on the ethnic group. ${ }^{3}$

Ideally, carrier detection programs are limited to disorders in which the detectability of carriers is $>90 \%$ to $95 \% .{ }^{4}$ However, this was not possible for CF in most ethnic groups without screening for a burdensome number of mutations. Although the demand for screening was great, widespread

\footnotetext{
From the ${ }^{1}$ Department of Human Genetics, Mount Sinai School of Medicine, New York, NY; and ${ }^{2}$ Dor Yeshorim, Brooklyn, NY.

Robert J Desnick, PhD, MD, Professor and Chairman, Department of Human Genetics, Mount Sinai School of Medicine, Box 1498, Fifth Ave at 100th St, New York 10029.

Received: May 13, 2004

Accepted: June 7, 2004
}

DOI: 10.1097/01.GIM.0000139510.00644.F7 population screening was not actually recommended by the American College of Obstetrics and Gynecology (ACOG) and American College of Medical Genetics (ACMG) until 2001.5 Based on a frequency of at least $0.1 \%$ of mutant alleles in a large CF patient database, a panel of 25 mutations was recommended even though the sensitivity was still below $90 \%$ in most ethnic groups. ${ }^{6}$ The results of screening with this mutation panel were reviewed in $2002^{7}$ and most recently, in this issue. $^{8}$

The Ashkenazi Jewish (AJ) population represents a unique group for genetic screening as common mutations occur in prevalent recessive diseases due to founder effect and/or selection. ${ }^{9,10}$ With regard to CF, five CFTR mutations (W1282X, $\Delta \mathrm{F} 508, \mathrm{G} 542 \mathrm{X}, 3849+10 \mathrm{~kb} \mathrm{C}>\mathrm{T}, \mathrm{N} 1303 \mathrm{~K}$ ) account for $97 \%$ of the mutant alleles in AJ CF patients. ${ }^{11}$ This population has a very high acceptance rate for genetic screening and has had a positive experience with carrier screening, beginning with TaySachs disease in $1970 .{ }^{12,13}$

In this study, we report our experiences with CF carrier screening in the AJ population using two different approaches: premarital (Dor Yeshorim, DY) and prenatal screening (Mount Sinai School of Medicine, MSSM). DY, which was founded in 1983 to meet the unique concerns of the Orthodox 
Jewish community, began premarital screening in 1983 for Tay-Sachs. ${ }^{14} \mathrm{CF}$ was added to their premarital testing panel in 1993. ${ }^{15}$ The Genetic Testing Laboratory at MSSM has been conducting prenatal CF carrier screening since 1992 and has performed over $60,000 \mathrm{CF}$ tests. ${ }^{16}$ Both programs initially screened for five, reported common AJ mutations (W1282X, $\Delta$ F508, G542X, 3849+10kb C > T, N1303K). ${ }^{11}$ In 2000, DY observed the presence of the D1152H CF mutation in the AJ population and, therefore, added this mutation along with 1717-1 G $>$ A to its routine AJ screening panel. At that time it was thought that 1717-1 G>A may be a common AJ mutation. In addition, DY screened $\approx 7,000100 \% \mathrm{AJ}$ individuals for up to 87 CF mutations. In 2001, MSSM began screening the AJ population for the remaining $25 \mathrm{ACMG}$ recommended panethnic mutations along with $\mathrm{D} 1152 \mathrm{H}$.

\section{MATERIALS AND METHODS}

\section{Screenees}

The participants in the DY program presented in this study were tested for CF between January 1993 through December 2003 and were $100 \%$ AJ. DY samples were coordinated through two centers in Brooklyn, NY and Jerusalem, Israel. Approximately $45 \%$ of the samples were from the greater New York metropolitan area, $\approx 5 \%$ were from the rest of North America, $\approx 45 \%$ were from Israel, and the remaining $5 \%$ were primarily from Europe.

The screenees included in the MSSM study represent a subset of patients who were referred to our laboratory from 1997 through March of 2004 for prenatal CF carrier screening and identified themselves as $100 \%$ AJ. For the majority of these screenees, both members of a couple were tested. In addition, a second MSSM subset included 7393 screenees who reported $<$ $100 \% \mathrm{AJ}$ descent or did not indicate ethnic origin, but also requested testing for at least one other $\mathrm{AJ}$ recessive disease. The second subset was tested for the 25 ACMG recommended CFTR panethnic mutation panel and $\mathrm{D} 1152 \mathrm{H}$.

\section{Mutation analysis}

DY screening was performed at several laboratories including the Kleeberg DNA Laboratory of the Baylor College of Medicine, Houston, Texas; Genzyme Genetics, Westborough, Massachusetts; Hadassah Hospital/Hebrew University, Jerusalem, Israel; Integrated Genetics, Framingham, Massachusetts; MSSM, New York, New York; and Cellmark Diagnostics, United Kingdom. The laboratories can be contacted directly for specific DNA analysis protocols. For the DY cohort, all individuals were initially tested for five mutations (W1282X, $\Delta$ F508, G542X, 3849+10kb C > T, N1303K). Subsequently, the DY panel was increased to seven with the addition of D1152H and 1717-1G $>$ A. Other mutations were screened (12 to 87 ) in an additional subset of 7,111 100\% $\mathrm{AJ}$ individuals to determine other mutation frequencies. In addition to the individuals tested for CF, over 13,000 control samples with known genotypes were blindly analyzed at these laboratories for quality assurance.
At MSSM, for the period January 1997 through December 2000 for which data and ethnic information are available, five mutations (W1282X, $\Delta \mathrm{F} 508, \mathrm{G} 542 \mathrm{X}, 3849+10 \mathrm{~kb} \mathrm{C}>\mathrm{T}$, N1303K) were analyzed by PCR amplification and restriction enzyme analyses. From January 2001, the panel was expanded to 26 mutations (the ACMG recommended panethnic panel plus D1152H). Testing was performed by multiplex PCR amplification and allele specific hybridization analyses. ${ }^{17}$

\section{RESULTS}

Table 1 summarizes the number of $100 \% \mathrm{AJ}$ screenees tested and the number and frequency for each of the seven routinely tested CF mutations among these individuals in the DY and MSSM programs as well as the combined mutation frequencies and the frequencies of these mutations in two previous studies. The carrier frequency for all seven mutations was 1 in 22.8 and 1 in 22.9 among the DY and MSSM screenees, respectively, for a combined overall frequency of 1 in 22.8 (or 0.0438). In both programs, the frequency of each mutation was remarkably similar. W1282X was most frequently detected by both programs with a carrier frequency of $\approx 1$ in 50 (or $\approx 0.020)$. $\Delta$ F508 was second most frequent, found in $\approx 1$ in 82 individuals tested (0.012). Of note, the third most common mutation, D1152H, was detected in about 1 in 190 of the 44,530 screenees tested (0.0053). This mutation was the most recently added to the panels of both programs. The G542X, 3849+10 kb C > T, and N1303K were tested in over 117,000 screenees and occurred at similar frequencies in both programs, with overall detection rates of 1 in 413 (0.0024), 1 in 490 (0.0020), and 1 in 633 (0.0016), respectively. The 1717-1G $>$ A mutation was the least frequent with an overall frequency of $\approx 1$ in 6,700 among 60,191 screenees (or 0.00015). For the five mutations (W1282X, $\Delta \mathrm{F} 508, \mathrm{G} 542 \mathrm{X}, 3849+10 \mathrm{~kb} \mathrm{C}>\mathrm{T}, \mathrm{N} 1303 \mathrm{~K}$ ) for which over 117,000 AJ screenees were tested, a total of 4,498 carriers were identified ( 1 in 26 or 0.038 ). For D1152H and 1717-1G $>$ A, 235 and 9 carriers were detected among 44,530 and 60,191 screenees, respectively. Table 1 also shows the mutation frequencies reported in two previous studies involving over 6,000 AJ individuals tested for at least the five common AJ mutations. The results differed slightly from this study. This may be due to sampling effects when screening for less common mutations. Table 2 shows the remarkably similar percentage of total CFTR mutations detected for each of the seven routinely tested mutations in the DY and MSSM programs.

In addition to the six common AJ mutations, the MSSM program has tested since 2001 for the mutations in the recommended panel of 25 panethnic mutations. Among the over 2,300 AJ screenees tested, one screenee was identified who carried $\mathrm{R} 117 \mathrm{H}$, one carried G551D and two carried I148T. The two I148T carriers were tested for the 3199del6 mutation by direct sequencing and were found to be negative for this putative-disease causing mutation. ${ }^{18-20}$ In the DY program, over $7,000100 \% \mathrm{AJ}$ individuals were screened for up to 87 mutations and only one screenee was found to be an I148T carrier and another was an $1898+1 \mathrm{G}>\mathrm{A}$ carrier. Five individuals 
Table 1

Carrier frequencies of seven routinely tested AJ CF mutations

\begin{tabular}{|c|c|c|c|c|c|c|c|}
\hline \multirow[b]{2}{*}{ CF mutation } & \multicolumn{2}{|c|}{ No. individuals tested } & \multicolumn{2}{|c|}{ Frequency } & \multirow[b]{2}{*}{$\begin{array}{l}\text { Combined } \\
\text { frequency }\end{array}$} & \multicolumn{2}{|c|}{ Previous studies } \\
\hline & DY & MSSM & DY & MSSM & & $\begin{array}{c}\text { Ref } 3 \\
\mathrm{n}=6076\end{array}$ & $\begin{array}{c}\text { Ref } 15 \\
\mathrm{n}=6850\end{array}$ \\
\hline W1282X & 110889 & 6247 & $\begin{array}{l}1 \text { in } 49.7 \\
(0.0201)\end{array}$ & $\begin{array}{l}1 \text { in } 48.8 \\
(0.0205)\end{array}$ & $\begin{array}{l}1 \text { in } 49.6 \\
(0.0202)\end{array}$ & $\begin{array}{l}1 \text { in } 48.2 \\
(0.0207)\end{array}$ & $\begin{array}{l}1 \text { in } 48.2 \\
(0.0207)\end{array}$ \\
\hline$\Delta \mathrm{F} 508$ & 110898 & 6247 & $\begin{array}{l}1 \text { in } 81.7 \\
(0.0122)\end{array}$ & $\begin{array}{l}1 \text { in } 86.8 \\
(0.0115)\end{array}$ & $\begin{array}{l}1 \text { in } 82.0 \\
(0.0122)\end{array}$ & $\begin{array}{l}1 \text { in } 79.7 \\
(0.0126)\end{array}$ & $\begin{array}{l}1 \text { in } 77.9 \\
(0.0128)\end{array}$ \\
\hline $\mathrm{D} 1152 \mathrm{H}$ & 42208 & 2322 & $\begin{array}{l}1 \text { in } 189.2 \\
(0.00528)\end{array}$ & $\begin{array}{l}1 \text { in } 193.5 \\
(0.00517)\end{array}$ & $\begin{array}{l}1 \text { in } 189.5 \\
(0.00528)\end{array}$ & $\begin{array}{l}1 \text { in } 113.5^{a} \\
(0.00881)\end{array}$ & $\mathrm{ND}^{b}$ \\
\hline G542X & 110893 & 6247 & $\begin{array}{l}1 \text { in } 410.7 \\
(0.00243)\end{array}$ & $\begin{array}{l}1 \text { in } 446.2 \\
(0.00224)\end{array}$ & $\begin{array}{l}1 \text { in } 412.5 \\
(0.00242)\end{array}$ & $\begin{array}{l}1 \text { in } 338.3 \\
(0.00296)\end{array}$ & $\begin{array}{l}1 \text { in } 506.3 \\
(0.00197)\end{array}$ \\
\hline $3849+10 \mathrm{~kb} \mathrm{C}>\mathrm{T}$ & 110888 & 6247 & $\begin{array}{l}1 \text { in } 490.7 \\
(0.00204)\end{array}$ & $\begin{array}{l}1 \text { in } 480.5 \\
(0.00208)\end{array}$ & $\begin{array}{l}1 \text { in } 490.1 \\
(0.00204)\end{array}$ & $\begin{array}{l}1 \text { in } 402.9 \\
(0.00248)\end{array}$ & $\begin{array}{l}1 \text { in } 607.6 \\
(0.00165)\end{array}$ \\
\hline N1303K & 110894 & 6247 & $\begin{array}{l}1 \text { in 637.2 } \\
(0.00157)\end{array}$ & $\begin{array}{l}1 \text { in } 567.9 \\
(0.00176)\end{array}$ & $\begin{array}{l}1 \text { in } 633.2 \\
(0.00158)\end{array}$ & $\begin{array}{l}1 \text { in } 913.3 \\
(0.00109)\end{array}$ & $\begin{array}{l}1 \text { in } 552.4 \\
(0.00181)\end{array}$ \\
\hline $1717-1 \mathrm{G}>\mathrm{A}$ & 57869 & 2322 & $\begin{array}{l}1 \text { in } 7233.6 \\
(0.000138)\end{array}$ & $\begin{array}{l}1 \text { in } 2322 \\
(0.000431)\end{array}$ & $\begin{array}{l}1 \text { in } 6687.9 \\
(0.000150)\end{array}$ & $\mathrm{ND}^{b}$ & $\mathrm{ND}^{b}$ \\
\hline $\begin{array}{l}\text { Five mutations } \\
\text { (Without } \mathrm{D} 1152 \mathrm{H} \\
\text { and } 1717-1 \mathrm{G}>\mathrm{A} \text { ) }\end{array}$ & & & $\begin{array}{l}1 \text { in } 26.1 \\
(0.0384)\end{array}$ & $\begin{array}{l}1 \text { in } 26.2 \\
(0.0381)\end{array}$ & $\begin{array}{l}1 \text { in } 26.1 \\
(0.0384)\end{array}$ & $\begin{array}{l}1 \text { in } 25.1 \\
(0.0398)\end{array}$ & $\begin{array}{l}1 \text { in } 25.7 \\
(0.0389)\end{array}$ \\
\hline Seven mutations & & & $\begin{array}{l}1 \text { in } 22.8 \\
(0.0438)\end{array}$ & $\begin{array}{l}1 \text { in } 22.9 \\
(0.0437)\end{array}$ & $\begin{array}{l}1 \text { in } 22.8 \\
(0.0438)\end{array}$ & & \\
\hline
\end{tabular}

$a_{n}=1305$.

${ }^{b}$ Not determined.

Table 2

Distribution of CF mutations in DY and MSSM carriers for five and seven common AJ mutations

\begin{tabular}{|c|c|c|c|c|c|c|}
\hline \multirow[b]{2}{*}{ CF mutation } & \multicolumn{3}{|c|}{$\%$ of $\mathrm{AJ}$ carriers ( 5 mutations) } & \multicolumn{3}{|c|}{$\%$ of AJ carriers ( 7 mutations) } \\
\hline & DY & MSSM & Combined & DY & MSSM & Combined \\
\hline W1282X & 52.3 & 53.8 & 53.1 & 45.9 & 46.9 & 46.4 \\
\hline$\Delta \mathrm{F} 508$ & 31.9 & 30.2 & 31.0 & 27.9 & 26.3 & 27.1 \\
\hline G542X & 6.3 & 5.9 & 6.1 & 5.5 & 5.1 & 5.3 \\
\hline $3849+10 \mathrm{~kb} \mathrm{C}>\mathrm{T}$ & 5.3 & 5.5 & 5.4 & 4.7 & 4.8 & 4.8 \\
\hline N1303K & 4.1 & 4.6 & 4.4 & 3.6 & 4.0 & 3.8 \\
\hline $\mathrm{D} 1152 \mathrm{H}$ & - & - & - & 12.1 & 11.8 & 12.0 \\
\hline $1717-1 \mathrm{G}>\mathrm{A}$ & - & - & - & 0.3 & 1.0 & 0.6 \\
\hline
\end{tabular}

from four families in the DY program were found to be compound heterozygotes for D1152H and W1282X (2 families), $\Delta$ F508 (1), or $3849+10 \mathrm{~kb} C>\mathrm{T}$ (1). Two individuals with the D1152H/W1282X genotype had digestive problems and growth retardation without significant pulmonary problems. Medical information on the other compound heterozygotes was not available.

Table 3 shows the distribution of CFTR mutations among the 263 carriers identified from 7393 screenees who were $<100 \% \mathrm{AJ}$ and simultaneously were tested for at least one other AJ recessive disease. The overall carrier frequency for the 13 CFTR mutations that were detected was 1 in 28.1. If $\mathrm{D} 1152 \mathrm{H}$ was not included, the carrier rate was 1 in 29.8. The additional mutations that were detected were $\mathrm{R} 117 \mathrm{H}(n=7)$, I148T (6), A455E (2), R334W (2), G551D (1), and R553X (1).

At MSSM, nine carrier couples were identified among the $100 \%$ AJ screenees, which was consistent with the number expected given the 1 in 23 to 1 in $26 \mathrm{CF}$ carrier frequency in the $\mathrm{AJ}$ population. For DY, 133 incompatible potential matches were identified. The frequency of carrier couples in the DY program was lower than expected due to the several year lag time from testing to couples requesting results. At MSSM, 43 pregnancies were monitored during this period for AJ carrier couples. Twelve pregnancies carrying an affected fetus were found and all couples elected to terminate the pregnancies. Of the remaining 31 prenatal diagnoses, 24 fetuses were heterozygotes and 


\section{Kornreich et al.}

Table 3

Frequency of CFTR mutations among screenees reporting $100 \% \mathrm{AJ}$ or $<100 \% \mathrm{AJ}$ descent who requested carrier testing for CF and at least one other AJ recessive disease

\begin{tabular}{|c|c|c|c|}
\hline CF mutation & $\begin{array}{l}\% \text { of mutations in carriers } \\
\text { reporting } 100 \% \mathrm{AJ} \text { descent } \\
\quad(\mathrm{n}=45,530-117,145)\end{array}$ & $\begin{array}{l}\% \text { of mutations among carriers } \\
\text { reporting }<100 \% \text { AJ descent } \\
\qquad(\mathrm{n}=7,393)\end{array}$ & $\begin{array}{l}\% \text { of Non-Hispanic Caucasian } \\
\text { CF patient chromosomes } \\
(\mathrm{n}=37,263)\end{array}$ \\
\hline W1282X & $46.4(\mathrm{n}=117,136)$ & 32.3 & 1.5 \\
\hline$\Delta \mathrm{F} 508$ & $27.1(\mathrm{n}=117,145)$ & 35.7 & 71.5 \\
\hline $\mathrm{D} 1152 \mathrm{H}$ & $12.0(\mathrm{n}=44,530)$ & 8.7 & 0.03 \\
\hline G542X & $5.3(\mathrm{n}=117,140)$ & 6.1 & 2.3 \\
\hline $3849+10 \mathrm{~kb} C>\mathrm{T}$ & $4.8(\mathrm{n}=117,135)$ & 4.9 & 0.7 \\
\hline N1303K & $3.8(\mathrm{n}=117,141)$ & 3.0 & 1.3 \\
\hline $1717-1 \mathrm{G}>\mathrm{A}$ & $0.6(\mathrm{n}=60,191)$ & 1.9 & 0.7 \\
\hline $\mathrm{R} 117 \mathrm{H}$ & $a$ & 2.7 & 0.8 \\
\hline $\mathrm{I} 148 \mathrm{~T}$ & $a$ & 2.3 & 0.05 \\
\hline R334W & - & 0.76 & 0.16 \\
\hline $\mathrm{A} 455 \mathrm{E}$ & - & 0.76 & 0.19 \\
\hline G551D & $a$ & 0.38 & 2.5 \\
\hline R553X & - & 0.38 & 1.0 \\
\hline
\end{tabular}

${ }^{a}$ These mutations were detected when screening $\approx 2,300100 \% \mathrm{AJ}$ individuals with the ACMG recommended panel. See text for details.

seven did not carry either parental mutation. These results were consistent with the expected Mendelian ratios $\left(\chi^{2}=1.0\right.$, $2 \mathrm{df})$.

\section{DISCUSSION}

Carrier screening for prevalent autosomal recessive diseases in the AJ population began with Tay-Sachs disease in 1970. ${ }^{12}$ The acceptance in the Jewish community was almost immediate, primarily because of the concerted educational and counseling efforts before screening. The Tay-Sachs carrier screening program has been enormously successful and is recognized as the prototype for the prevention of recessive diseases by preconceptual or prenatal carrier detection. ${ }^{12,13}$ In 1973, the MSSM prenatal carrier screening program began with TaySachs disease, added CF and Gaucher disease in 1992, and then increased its disease panel, as the common mutations were identified in prevalent Jewish genetic diseases. ${ }^{16}$ Currently, the MSSM screening panel tests for nine AJ recessive diseases (TaySachs, CF, Gaucher, Canavan, Niemann-Pick Type A, Fanconi anemia, Bloom syndrome, familial dysautonomia, mucolipidosis IV). The MSSM program routinely screens both members of a couple in order to reduce anxiety over a pending pregnancy, because $\approx 1$ in 5 screenees will be a carrier for one of the nine diseases.

DY, founded in 1983, was designed to meet the needs of the Orthodox Jewish community with the aim of preventing serious genetic diseases while upholding strict religious beliefs. DY offers genetic testing to youths with parental consent, with the majority of individuals being tested in high school or in a seminary. All testing is done confidentially and individuals are given a coded identification number when their sample is taken, and their birth date is recorded. If a couple is contemplating a marriage match, they provide their code numbers and birth dates to a central office. The members of the proposed match are informed whether they are compatible or not, and do not receive actual results if they are compatible. Therefore, most individuals who are CF carriers are not burdened with this information. However, if an incompatible potential match is identified, both individuals are informed of their carrier status and are provided with information about the disease. Counseling is provided to incompatible couples, if desired. This program has been highly successful in meeting its goal of preventing common genetic diseases in the religious AJ population.

Previous studies of $\mathrm{AJ}$ patients with $\mathrm{CF}$ indicated that screening for five mutations (W1282X, $\Delta \mathrm{F} 508, \mathrm{G} 542 \mathrm{X}$, $3849+10 \mathrm{~kb} C>\mathrm{T}, \mathrm{N} 1303 \mathrm{~K}$ ) would detect $97 \%$ of alleles causing $\mathrm{CF}$ in the $\mathrm{AJ}$ population. ${ }^{11}$ Based on the data presented in this study, the largest dataset on $\mathrm{AJ}$ carrier screening reported to date, the CF carrier frequency in the $100 \% \mathrm{AJ}$ population is about 1 in 26 for these five mutations (Table 1). The overall CF carrier frequency and the frequencies of the individual mutations were virtually identical among the DY and MSSM screenees. Of note, the frequency and distribution of the CF mutations in the AJ carriers differed from those in non-Hispanic Caucasian CF patients ${ }^{8}$ (Table 3). For example, W1282X was the most prevalent mutation among Ashkenazi Jews, present in $46.4 \%$ of $\mathrm{AJ}$ carriers, whereas it was present in only $1.5 \%$ of non-Hispanic Caucasian CF patients. ${ }^{8} \Delta$ F508, the most common mutation in non-Hispanic Caucasian CF pa- 
tients ( $71.5 \%$ of mutant alleles), ${ }^{8}$ represented in $27.1 \%$ of AJ carrier CF alleles.

The D1152H and 1717-1G $>$ A mutations were added to the DY screening panel in 2000 and MSSM added the remaining mutations in the ACMG panel of 25 panethnic mutations along with D1152H in 2001. D1152H has a carrier frequency of 1 in 190 (or 0.0053) in the AJ population, where it represents $12 \%$ of the CF carrier alleles. Functional studies indicated that $\mathrm{D} 1152 \mathrm{H}$, located in the intracytoplasmic loop connecting transmembrane domain 12 and nucleotide binding domain 2, did not alter the maturation of the CFTR protein, but interfered with proper gating of the chloride channel. ${ }^{21}$ Mutation $1717-1 G>A$ was included in the ACMG recommended CF panethnic mutation panel ( $0.7 \%$ of CF chromosomes) $)^{8}$ so it was routinely tested as part of the MSSM program as well as most of the academic and commercial laboratories who now test the DY screenees. The overall frequency of $1717-1 \mathrm{G}>\mathrm{A}$ observed in this study was about 1 in 6700 carriers, a low, but acceptable frequency for inclusion in the AJ panel. Of note, this mutation was not detected when over 7000 Israeli Jews were screened. ${ }^{3}$ When D1152H and 1717-1 G $>$ A were included, the overall AJ carrier frequency increased to 1 in 23.

When MSSM and DY testing laboratories introduced expanded screening panels, several other CF mutations were found among AJ screenees; these were R117H, G551D, I148T, and $1898+1 \mathrm{G}>\mathrm{A}$. Of interest, $\mathrm{R} 117 \mathrm{H}$ and G551D represented 0.8 and $2.5 \%$ of alleles in the non-Hispanic Caucasian CF patients, respectively, ${ }^{8}$ but were rare in the AJ population (each seen only once in over 2,300 screenees). In addition, three screenees were found to carry I148T. However, the two individuals identified at MSSM were found to be negative for the 3199del6 mutation that presumably is the disease-causing mutation in cis with the I148T variant. ${ }^{18-20}$ Of the five individuals identified by DY who were compound heterozygotes for $\mathrm{D} 1152 \mathrm{H}$ and $\mathrm{W} 1282 \mathrm{X}, \Delta \mathrm{F} 508$ or $3849+10 \mathrm{~kb} \mathrm{C}>\mathrm{T}$, anecdotal information from the two individuals from one family with the D1152H/W1282X genotype indicated a mild form of CF. Information could not be obtained from the other families due to confidentiality. However, previous reports indicate that the D1152H mutation together with a classic CF mutation results in variant $\mathrm{CF}$ phenotypes, including an adult (D1152H/ $\Delta$ F508) with mild pulmonary disease. ${ }^{22}$ The D1152H/DF508 genotype also has been reported in four adults with mild pulmonary symptoms, two with Pseudomonas colonization, and another with pancreatic insufficiency. ${ }^{23,24}$ This mutation has also been observed in males with CBAVD. ${ }^{25,26}$ However, this mutation was present along with G542X in a fetus with hyperechogenic bowel loops and meconium ileus, suggesting a more severe course would occur in this case. ${ }^{27}$

In contrast to the limited number of CFTR mutations that were detected in screenees who reported themselves to be $100 \% \mathrm{AJ}$, the distribution of CFTR mutations in the over 7,000 MSSM screenees who were of $<100 \%$ AJ descent differed significantly. Twelve of the 25 ACMG-recommended panethnic mutations were detected. Of interest, W1282X, which was the most prevalent mutation seen in the $100 \% \mathrm{AJ}$ cohort $(46.4 \%$ of
CFTR mutations), was observed in $32.3 \%$ of the population with $<100 \% \mathrm{AJ}$ descent. In contrast, $\Delta \mathrm{F} 508$ was the most common mutation detected (35.7\% of mutations) in this group. Based on the proportion of these mutations in the two groups of screenees, it could be estimated that $\approx 30 \%$ of individuals who requested Jewish genetic disease screening probably were of mixed ancestry or the spouses in couples where one partner was of AJ descent.

Based on the results of these studies, it is recommended that premarital/prenatal carrier screening for CF be performed by testing the five common AJ CFTR mutations (W1282X, DF508, G542X, 3849+10kb C>T, N1303K), along with $\mathrm{D} 1152 \mathrm{H}$, for individuals who report that they are $100 \% \mathrm{AJ}$. Genetic counseling for at risk couples carrying D1152H and a classic CF mutation should include the latest clinical information about CF patients with the D1152H lesion for informed decision-making. Of note, the CF carrier frequencies were virtually the same among the DY Orthodox and MSSM AJ screenees who participated in the premarital and prenatal carrier screening programs, respectively. Approximately half of the MSSM 100\% AJ screenees were also tested for the ACMG 25 panethnic mutation panel and only two had another mutation, excluding I148T. In contrast, when the MSSM screenees did not report $100 \%$ AJ descent, or when one member of the couple was not of AJ descent, the panel did identify other CF mutations. Therefore, in the later situations, it is recommended that the revised ACMG screening panel of 23 mutations and $\mathrm{D} 1152 \mathrm{H}$ (with proper counseling) be used for CF carrier screening.

\section{ACKNOWLEDGMENTS}

This study was supported in part by a NIH grant from the National Center for Research Resources to the Mount Sinai General Clinical Research Center (5 M01 RR00071) and the Mount Sinai Center for Jewish Genetic Diseases. The authors wish to thank Adebukola Olukoga and Asghar Bajwa for their expert technical assistance. Valuable assistance with data analysis was provided by Philippe Sevin at Medgis-PSA. We are indebted to the devotion of our genetic counselors; Randi Zinberg, Julie McGlynn and Sayeh Farivah.

\section{References}

1. Hospital for Sick Children. Toronto, Cystic Fibrosis Mutation Database. Available at: http://www.genet.sickkids.on.ca/cftr/.

2. Bobadilla JL, Macek M, Fine JP, Farrell PM. Cystic fibrosis: a worldwide analysis of CFTR mutations-correlation with incidence data and application to screening. Hum Mut 2002;19:575-606.

3. Orgad S, Neumann S, Loewenthal R, Netanelov-Shapira I, Gazit E. Prevalence of cystic fibrosis mutations in Israeli Jews. Genet Test 2001;5:47-52.

4. ASHG. Statement on cystic fibrosis carrier screening. Am J Hum Genet 1992;51: 1443-1444.

5. American College of Obstetrics and Gynecology, and American College of Human Genetics, Preconception and prenatal carrier screening for cystic fibrosis. Clinical and laboratory guidelines. Washington, DC: American College of Obstetrics and Gynecology, 2001.

6. Grody WW, Cutting GR, Klinger KW, Richards CS, Watson MS, Desnick RJ. Laboratory standards and guidelines for population-based cystic fibrosis carrier screening. Genet Med 2001;3:149-154.

7. Richards CS, Bradley LA, Amos J, Allitto B, Grody WW, Maddalena A et al. Standards and Guidelines for CFTR Mutation Testing. Genet Med 2002;3:379-391. 


\section{Kornreich et al.}

8. Watson MS, Cutting GR, Desnick RJ, Driscoll DA, Klinger K, Mennuti M et al. Cystic fibrosis population carrier screening: 2004 revision of ACMG's mutation panel. Genet Med 2004;6:000-000.

9. Goodman RM, Motulsky AG. Genetic diseases among the Ashkenazi Jews. New York, Raven Press, 1979.

10. Risch N, Tang J, Katzenstein H, Ekstein J. Geographic distribution of disease mutations in the Ashkenazi Jewish population supports genetic drift over selection. Am J Hum Genet 2003;72:812-822.

11. Abeliovich D, Lavon IP, Lerer I, Cohen T, Springer C, Avital A et al. Screening for five mutations detects $97 \%$ of cystic fibrosis (CF) chromosomes and predicts a carrier frequency of 1:29 in the Jewish Ashkenazi Population. Am J Hum Genet 1992;51:951-956

12. Kabak M, Lim-Steele J, Dabholkar D, Brown D, Levy N, Zeiger K. Tay-Sachs diseaseCarrier screening, prenatal diagnosis, and the molecular era: An international prospective, 1970-1993. JAMA 1993;270:2307-2315.

13. Desnick RJ, Kaback MM. Future perspectives for Tay-Sachs disease. Adv Genet 2001; 44:349-356.

14. Ekstein J, Katzenstein H. The Dor Yeshorim story: community-based carrier screening for Tay-Sachs disease. Adv Genet 2001;44:297-310.

15. Abeliovich D, Quint A, Weinberg N, Verchezon G, Lerer I, Ekstein J et al. Cystic fibrosis heterozygote screening in the orthodox community of Ashkenazi Jews: the Dor Yesharim approach and heterozygote frequency. Eur J Hum Genet 1996;4:338 341.

16. Eng CM, Schechter C, Robinowitz J, Fulop G, Burgert T, Levy B et al. Prenatal genetic carrier testing using triple disease screening. JAMA 1997;278:1268-1272.

17. Edelmann L, Hashmi G, Seul M, Kornreich R, Desnick RJ. Cystic fibrosis carrier screening: Validation of a novel method using beadchip technology. Genet Med 2004;6:000-000.
18. Rohlfs EM, Zhou Z, Sugarman EA, Heim RA, Pace RG, Knowles MR et al. The I148T CFTR allele occurs on multiple haplotypes: a complex allele is associated with cystic fibrosis. Genet Med 2002;4:319-323.

19. Strom CM, Huang D, Buller A, Redman J, Crossley B, Anderson B et al. Cystic fibrosis screening using the College panel: Platform comparison and lessons learned from the first 20,000 samples. Genet Med 2002;4:289-296.

20. Strom CM, Huang D, Chen C, Buller A, Peng M, Quan F et al. Extensive sequencing of the cystic fibrosis transmembrane regulator gene: assay validation and unexpected benefits of developing a comprehensive test. Genet Med 2003;5:9-14.

21. Vankeerberghen A, Wei L, Teng H, Jaspers M, Cassiman JJ, Nilius B et al. Characterization of mutations located in exon 18 of the CFTR gene. FEBS Lett 1998;437:1-4.

22. Feldmann D, Rochemaure J, Plouvier E, Magnier C, Chauve C, Aymard P. Mild course of cystic fibrosis in an adult with the D1152H mutation. Clin Chem 1995;41: 1675 .

23. Feldmann D, Couderc R, Audrezet MP, Ferec C, Bienvenu T, Desgeorges M et al. CFTR genotypes in patients with normal or borderline sweat chloride levels. Hum Mutat 2003;22:340-346.

24. Lebecque P, Leal T, De Boeck C, Jaspers M, Cuppens H, Cassiman JJ. Mutations of the cystic fibrosis gene and intermediate sweat chloride levels in children. Am J Respir Crit Care Med 2002;165:757-761.

25. Kerem B, Chiba-Falek O, Kerem E. Cystic fibrosis in Jews: Frequency and mutation distribution. Genet Testing 1997;1:35-39.

26. Claustres M, Guittard C, Bozon D, Chevalier F, Verlingue C, Ferec C et al. Spectrum of CFTR mutations in cystic fibrosis and in congenital absence of the vas deferens in France. Hum Mutat 2000;16:143-156.

27. Orgad S, Berkenstadt M, Achiron R, Yahav Y, Gazit E, Barkai G et al. Hyperechogenic bowel loops and meconium ileus in a fetus carrying the D1152H and G542X cystic fibrosis CFTR mutations. Prenat Diagn 2002;22:633-637. 